\title{
Influence of Organoclay on the Flame Retardancy and Thermal Insulation Property of Expandable Graphite/Polyurethane Foam
}

\author{
Nhung Hac Thi $\mathbb{D}^{1,2}$ Duy Linh Pham, ${ }^{1}$ Nguyen Thi Hanh $\mathbb{D}^{1,2}$ Ho Thi Oanh $\mathbb{D},{ }^{1,2}$ \\ Thi Hai Yen Duong, ${ }^{1}$ Thanh Nhan Nguyen $\mathbb{1}{ }^{1},{ }^{1}$ Nguyen Duc Tuyen $\left(\mathbb{D},{ }^{1}\right.$ Dinh Long Phan, ${ }^{1,2}$ \\ Ha Thu Trinh, ${ }^{1}$ Ha Tran Nguyen, ${ }^{3}$ Tung Ngo Trinh, ${ }^{1}$ and Mai Ha Hoang $\mathbb{D}^{1,2}$ \\ ${ }^{1}$ Institute of Chemistry, Vietnam Academy of Science and Technology, 18 Hoang Quoc Viet, Cau Giay, Hanoi, Vietnam \\ ${ }^{2}$ Graduate University of Science and Technology, Vietnam Academy of Science and Technology, 18 Hoang Quoc Viet, Cau Giay, \\ Hanoi, Vietnam \\ ${ }^{3}$ Faculty of Materials Technology, Ho Chi Minh City University of Technology, Vietnam National University, 268 Ly Thuong Kiet, \\ District 10, Ho Chi Minh City, Vietnam
}

Correspondence should be addressed to Mai Ha Hoang; hoangmaiha@ich.vast.vn

Received 15 March 2019; Accepted 28 May 2019; Published 17 June 2019

Guest Editor: Nguayen Van Noi

Copyright (c) 2019 Nhung Hac Thi et al. This is an open access article distributed under the Creative Commons Attribution License, which permits unrestricted use, distribution, and reproduction in any medium, provided the original work is properly cited.

\begin{abstract}
The rigid polyurethane foams (RPUFs) filled with organoclay cloisite 20A and expandable graphite (EG) were prepared by the one-step expanding foam method. Flame behavior, mechanical properties, and thermal conductivity of the composites were investigated. The vertical burning test (UL-94V) and limiting oxygen index (LOI) showed that the flame retardancy was increased proportionally with the content of EG in PU composite. However, the presence of EG filler impaired the thermal insulation and the compressive strength of the composite. In this report, we proved that organoclay could improve the compressive strength, thermal insulation, and flame retardancy of EG/polyurethane composites. This work can contribute to the development of environment-friendly flame-retardant products for green growth.
\end{abstract}

\section{Introduction}

Rigid polyurethane foams (RPUFs) are commonly used in the construction industry as an insulating and soundproof barrier because of their low thermal conductivity, low density, high compression strength, and excellent adhesion $[1,2]$. Additionally, RPUF can be frequently found as an insulation layer in pipes, tanks, refrigerators, boats, and aircraft $[3,4]$. However, RPUFs are flammable materials and release polluted gases if burned, limiting its application [5].

The most effective and simplest method to improve the flame-retardant properties of RPUF is the addition of flameretardant additives into the polymer matrix. The common additives include halogen, phosphorus, and nitrogen compounds [6-12]. Unfortunately, these flame-retardant compounds generate toxic gases in the burning process which are harmful to people and the environment $[13,14]$.

Expandable graphite (EG) is an intumescent fire retardant material and has been widely utilized in the polyurethane matrix. When EG is exposed to a heat source, it will be expanded to a carbonaceous layer on the surface of the PU composite. This char layer prevents oxygen diffusion and mass and heat transfer between the flame and PU matrix, thus discontinuing the self-sustained combustion of the composite [15-20]. Modesti et al. [13, 16] investigated the fire behavior of low-density EG/PUF and proved that good flame-retardant composites could be acquired by increasing EG loading. However, the presence of EG reduced the compressive strength of EG/PUF composites [13, 15, 1921]. Moreover, it was also found that the thermal 
conductivity of the EG/PUF composites increased in comparison with pure PUF $[13,15,20-24]$. The higher thermal conductivity could hamper the application of PUFs as a thermal insulation material. So, it is necessary to develop novel EG/RPUF composites that meet the requirement of high flame retardancy while retaining mechanical strength and thermal insulation. Nonetheless, there have been few reports devoted to solving the problem.

Organoclay is known as a common reinforcement for polymers because of its unique properties such as nanoscale lamellar structures, high aspect ratio, and high tensile strength $[25,26]$. Besides, it was also found that the flameretardant properties of PU foam were enhanced upon the incorporation of nanoclay $[27,28]$. In this work, we demonstrated that incorporation of organoclay into EG/PU composite is an effective, simple, and scalable method to improve the mechanical, thermal insulation, and flameretardant properties of the polyurethane foams.

\section{Materials and Methods}

2.1. Materials. The polyol used for RPUF preparation was a polypropylene glycol with the viscosity at $20^{\circ} \mathrm{C}=1500 \pm 300 \mathrm{cps}$ (MCNS Inc.) containing $n$-pentane (technical grade) as a blowing agent. The isocyanate used was $4,4^{\prime}$-diphenylmethane diisocyanate (MDI) with $\mathrm{NCO}$ $\%=31 \%$ and average functionality $=2.8$ (Tosoh Corporation, Japan). Additional components used for RPUF composites were expandable graphite flakes (EG): +50 mesh $(>300 \mu \mathrm{m}$, $\geq 75 \%$ minimum), $\mathrm{pH}=5 \div 10$ (Sigma-Aldrich), and cloisite 20A: d-spacing $(001)=31.5 \AA$ (Southern Clay Products Inc., Texas, USA).

2.2. Preparation of the Rigid Foam. Rigid polyurethane foam was prepared by the one-step expanding foam method using cast molding. EG and cloisite $20 \mathrm{~A}$ were dispersed into the polyol before adding isocyanate. Polyol, blowing agent, and additives were mixed and stirred together until a uniform mixture was obtained. Afterward, a certain amount of isocyanate MDI $(\mathrm{MDI} / \mathrm{polyol}=1.4 \mathrm{w} / \mathrm{w})$ was added into the mixture with vigorous stirring for $10 \mathrm{~s}$. The mixture was then quickly poured into a mold to produce PU foam. For the completion of the polymerization between MDI and polyol, the molds containing PU were kept in an oven at $70^{\circ} \mathrm{C}$ for $24 \mathrm{~h}$. Finally, the PU foams were separated from the mold and the hard surface of the foams was removed. The components of the flame-retardant foam are given in Table 1.

\subsection{Characterizations. The horizontal and vertical burning} tests were carried out with the GT-MC35F-2 horizontal and vertical flame chamber, according to the standard horizontal burning test (ASTMD 635-98) and the standard vertical burning test (ASTMD 3801-96). The size of the specimen was $130 \times 13 \times 3 \mathrm{~mm}^{3}$ (length $\times$ width $\times$ thickness). Limiting oxygen index (LOI) was determined by a Yasuda 214 instrument on the sample whose size was $130 \times 10 \times 10 \mathrm{~mm}^{3}$ according to ASTMD 2863-97. Thermal gravimetric analysis
(TGA) was performed on a LABSYS Evo STA under air with the heating rate of $10^{\circ} \mathrm{C} \cdot \mathrm{min}^{-1}$ from $30^{\circ} \mathrm{C}$ to $800^{\circ} \mathrm{C}$. The thermal conductivity of the foams was measured with a THB-500-Transient hot bridge (Linseis) instrument according to standard DIN EN 993-15. The size of the samples was $60 \times 40 \times 5 \mathrm{~mm}^{3}$. The sensor was sandwiched between two sheets of the sample. The compression test of the composites was taken on an Instron 3383 system, and the size of samples was $50 \times 50 \times 50 \mathrm{~mm}^{3}$ according to the standard ISO 4898. The rate of compression was $5 \mathrm{~mm} \cdot \mathrm{min}^{-1}$. The surface morphology of RPUF composites before and after burning was observed by using a Hitachi S-4800 scanning electron microscope instrument with an accelerating voltage of $5 \mathrm{kV}$ at the room temperature. Transmission electron micrographs (TEM) were taken by a JEM 1400 (JEOL, Japan) of $70 \mathrm{~nm}$ thick layers of the composites. The TEM specimen was prepared by an epoxy embedding method at ambient temperature. The crystal structures of PU composites were determined by AD8 Advance diffractometer with scan detectors and $\mathrm{Cu} \mathrm{Ka}$ radiation $(\lambda=1.5406 \AA)$, a tube voltage of $40 \mathrm{kV}$, and a current of $40 \mathrm{~mA}$.

\section{Results and Discussion}

3.1. Flame-Retardant Properties of the Foams. Flame-resistant properties of RPUF composites with different contents of EG and Cloisite 20A were investigated by the horizontal-vertical burning test (UL-94) and the LOI test. The results of the burning test are presented in Figure 1 and Table 2. The surface of burned composites was covered by worm-like structures of the expanded graphite char layer which could protect the PU matrix. The horizontal test (Figure 1(a) and Table 2) exhibited that the pure RPUF burned very fast and completely. By contrast, the flame of EG-filled composites was stopped in front of the first mark and the flame retardancy of the EG-containing composite reached UL94HB rating. In the case of the vertical burning test, the neat RPUF and the RPUF filled with $5 \mathrm{wt} \%$ EG burnt up to the holding clamp, so the samples failed according to the classification of UL94V test. When the loading of EG was $10 \mathrm{wt} \%$ or higher, the burning of samples stopped immediately after taking out from the flame source, implying that the sample passed V0-rating (Figure 1(b)).

The flame retardancy of PU composites was further investigated by LOI experiments (Figure 2). According to the ASTMD 2863-97 standard, a material is classified as flame retardant if the LOI value is above $23 \%$. As indicated in Figure 2, the inclusion of EG significantly enhanced the flame retardancy of the foam, changing pure RPUF from a highly flammable material (LOI value: $20.2 \%$ ) to a flameresistant composite. The LOI value was increased proportionally with the content of EG. In particular, RPUF with 20 wt\% EG showed the LOI value up to $30.5 \%$ (Table 2).

To clearly understand the flame-retardant behavior, the structure of EG/RPUF composites before and after burning test was observed by SEM images (Figure 3). Initially, EG stiff flakes with the size of $300-500 \mu \mathrm{m}$ was distributed at some locations in the PU matrix as shown in Figures 3(a) and 3(b). 
TABLE 1: Compositions of RPUF samples.

\begin{tabular}{|c|c|c|c|c|c|}
\hline \multirow{2}{*}{ No. } & \multirow{2}{*}{ Samples } & \multirow{2}{*}{ Polyol (wt \%) } & \multirow{2}{*}{ MDI (wt \%) } & \multicolumn{2}{|c|}{ Flame-retardant additives } \\
\hline & & & & EG (wt \%) & Cloisite 20A (wt \%) \\
\hline 1 & Pure RPUF & 41.67 & 58.33 & - & - \\
\hline 2 & EG5-RPUF & 39.58 & 55.42 & 5 & - \\
\hline 3 & EG10-RPUF & 37.50 & 52.50 & 10 & - \\
\hline 4 & EG15-RPUF & 35.42 & 49.58 & 15 & - \\
\hline 5 & EG15-20A2.5-RPUF & 34.38 & 48.12 & 15 & 2.5 \\
\hline 6 & EG15-20A5-RPUF & 33.33 & 46.67 & 15 & 5 \\
\hline 7 & EG17.5-RPUF & 34.38 & 48.12 & 17.5 & - \\
\hline 8 & EG17.5-20A2.5-RPUF & 33.33 & 46.67 & 17.5 & 2.5 \\
\hline 9 & EG20-RPUF & 33.33 & 46.67 & 20 & - \\
\hline
\end{tabular}

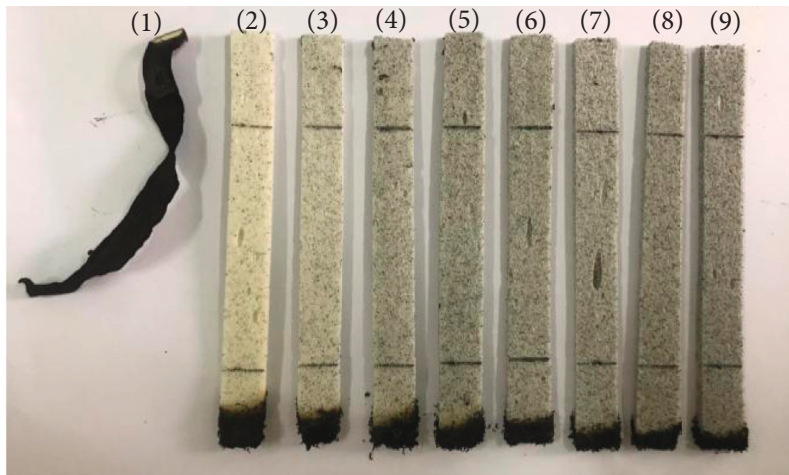

(a)

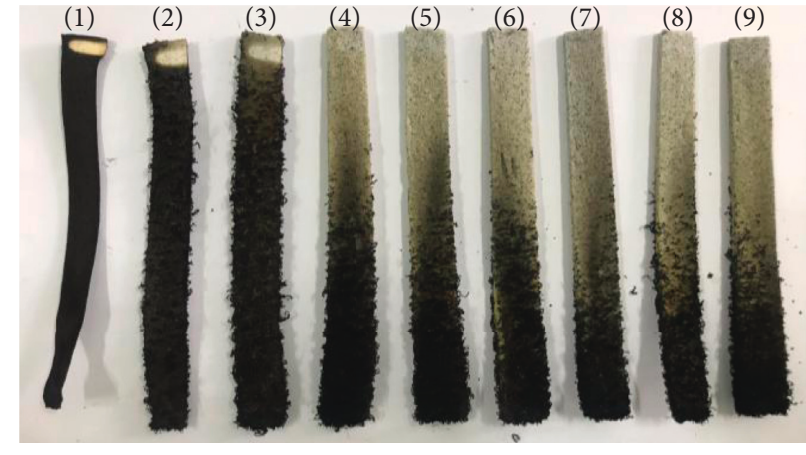

(b)

FIGURE 1: Images of the samples after the horizontal (a) and vertical burning tests (b): (1) pure RPUF; (2) EG5-RPUF; (3) EG10-RPUF; (4) EG15-RPUF; (5) EG15-20A2.5-RPUF; (6) EG15-20A5-RPUF; (7) EG17.5-RPUF; (8) EG17.5-20A2.5-RPUF; (9) EG20-RPUF.

TABLE 2: Flame-retardant and physical properties of RPUF composites.

\begin{tabular}{|c|c|c|c|c|c|c|}
\hline No. & Sample & HB-rating & $\begin{array}{c}\mathrm{V}- \\
\text { rating }\end{array}$ & LOI (vol\%) & Stress at $10 \%$ strain $(\mathrm{Mpa})$ & Thermal conductivity $\left(\mathrm{W} \cdot \mathrm{m}^{-1} \cdot \mathrm{K}^{-1}\right)$ \\
\hline 1 & Pure RPUF & $300 \mathrm{~mm} / \mathrm{min}$. -fail & Fail & 20.2 & 0.2464 & 0.028 \\
\hline 2 & EG5-RPUF & $\mathrm{HB}$ & Fail & 23.7 & 0.2421 & 0.036 \\
\hline 3 & EG10-RPUF & HB & $\mathrm{V}-0$ & 25.9 & 0.2367 & 0.047 \\
\hline 4 & EG15-RPUF & $\mathrm{HB}$ & $\mathrm{V}-0$ & 28.1 & 0.2313 & 0.053 \\
\hline 5 & EG15-20A2.5-RPUF & $\mathrm{HB}$ & $\mathrm{V}-0$ & 28.5 & 0.2485 & 0.048 \\
\hline 6 & EG15-20A5-RPUF & $\mathrm{HB}$ & $\mathrm{V}-0$ & 28.7 & 0.2536 & 0.041 \\
\hline 7 & EG17.5-RPUF & $\mathrm{HB}$ & $\mathrm{V}-0$ & 29.2 & 0.2284 & 0.055 \\
\hline 8 & $\begin{array}{c}\text { EG17.5-20A2.5- } \\
\text { RPUF }\end{array}$ & $\mathrm{HB}$ & $\mathrm{V}-0$ & 29.4 & 0.2426 & 0.05 \\
\hline 9 & EG20-RPUF & $\mathrm{HB}$ & $\mathrm{V}-0$ & 30.5 & 0.2217 & 0.058 \\
\hline
\end{tabular}

After burning, the surface of the composite was covered entirely by spongy expanded graphite (Figures 3(c) and 3(d)). This phenomenon was also reported in the previous literature which found that EG was expanded more than 100 times its original size under higher temperatures by fast volatilization of the intercalation $[29,30]$. The expanded graphite thus acted as a physical barricade which inhibited the oxygen diffusion and mass and heat transfer between the flame and PU matrix.

However, the presence of EG in PU foams increased the thermal conductivity and diminished the mechanical behavior of the composites. In order to solve this problem, we incorporated organoclay into EG/PU composites. The LOI test indicated that, with the same EG content, the clayadditive could lead to an increase of LOI value of EG/PU foam. In particular, in comparison with EG15-RPUF (LOI value of 28.1\%), EG15-20A2.5-RPUF, and EG15-20A5RPUF, samples displayed higher LOI values of $28.5 \%$ and $28.7 \%$, respectively. The similar behavior was observed when adding $2.5 \mathrm{wt} \%$ clay to EG17.5-RPUF. There may be two factors attributed to the enhancement in the LOI value of the EG/clay/RPUF composite. Firstly, clay increased the viscosity of polyol so the dispersion of the EG filler in the 


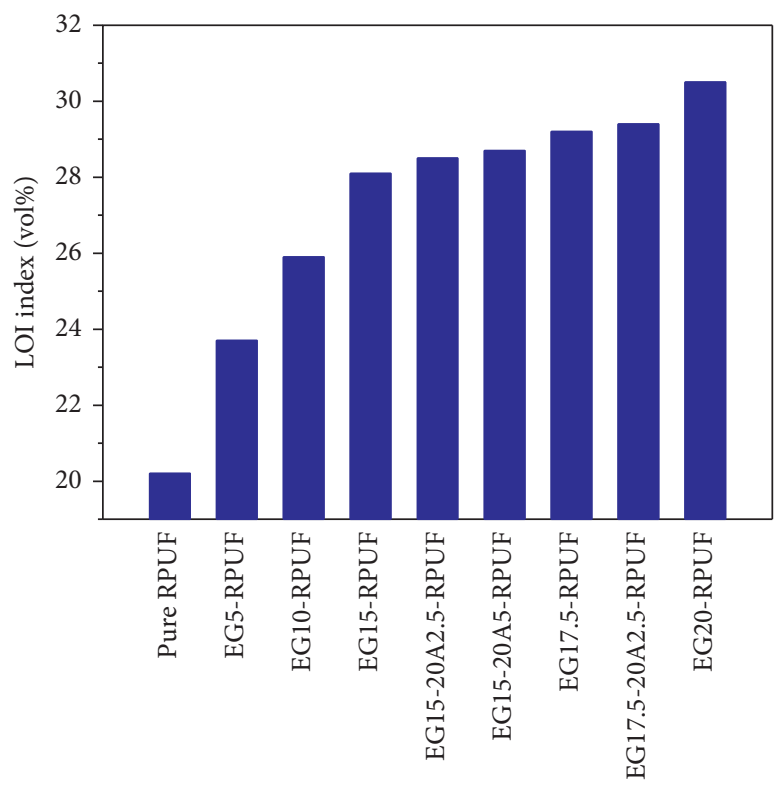

Figure 2: LOI values of the PU foams using different flame-retardant additives.

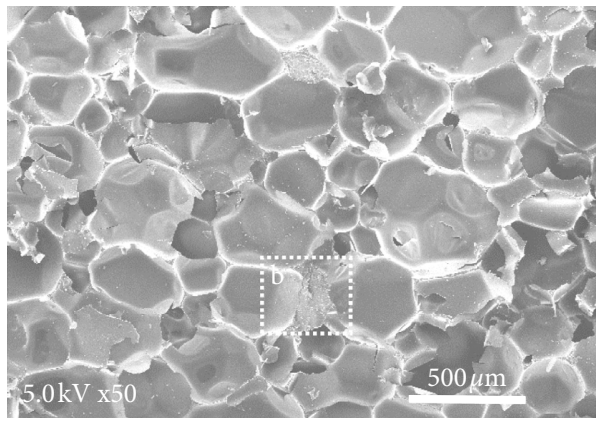

(a)

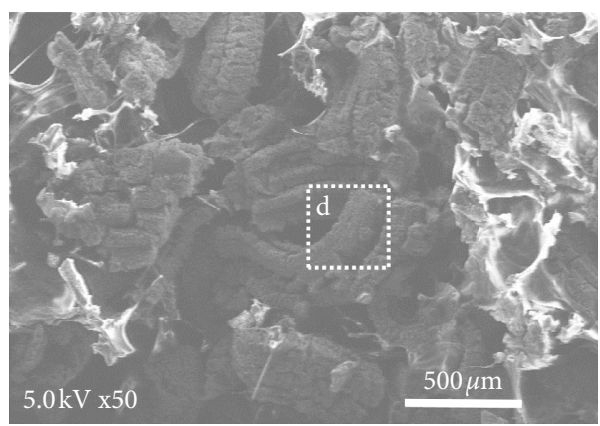

(c)

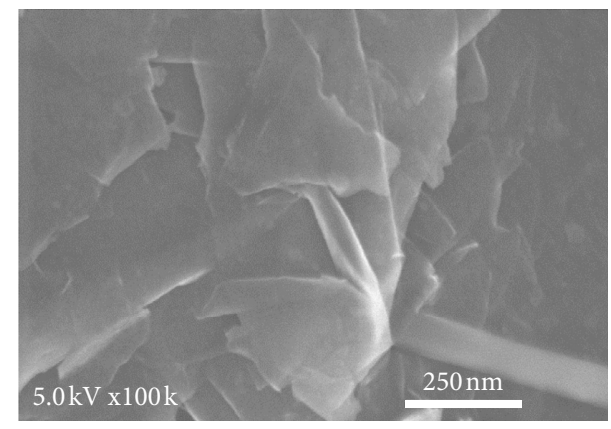

(b)

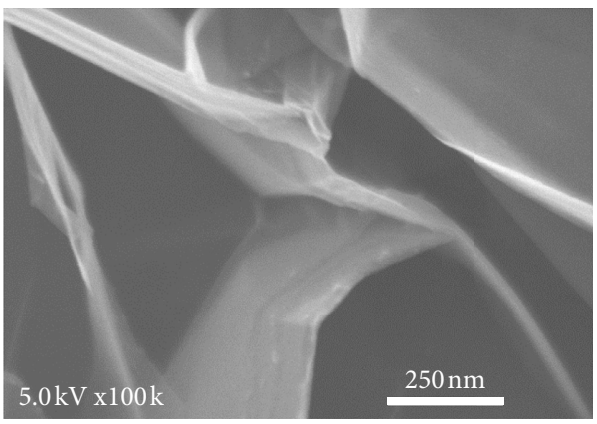

(d)

FIGURE 3: SEM micrographs of EG/RPUF composite before (a) and after (c) burning and their high magnification images (b) and (d), respectively.

polymer matrix was improved. Besides, as the burning occurs, organoclay forms a char layer on the surface of the materials, which prevents the heat transfer and the permeability of oxygen into the material as well as the evaporation of inflammable degradation products [31]. Thus, clay and EG exhibited a synergetic effect in the improvement of flame retardancy of PU composites.
3.2. Thermal Stability of the Composites. To better understand the role of EG and clay to the flame-retardant behavior of PU composite, the thermal stability of these composites was studied by TGA (Figure 4). The degradation of all samples consisted of two steps. The first maximum weight loss temperature, $T_{1 \max }$, of pure $\mathrm{PU}$ was about $330^{\circ} \mathrm{C}$ due to the depolycondensation of PU [32]. In the case of 


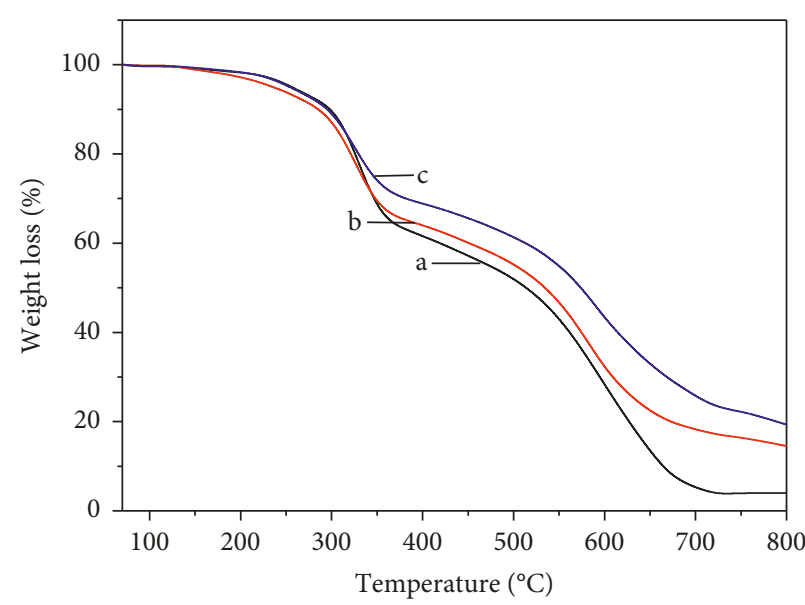

(a) Pure RPUF

(b) EG15-RPUF

(c) EG15-20A5-RPUF

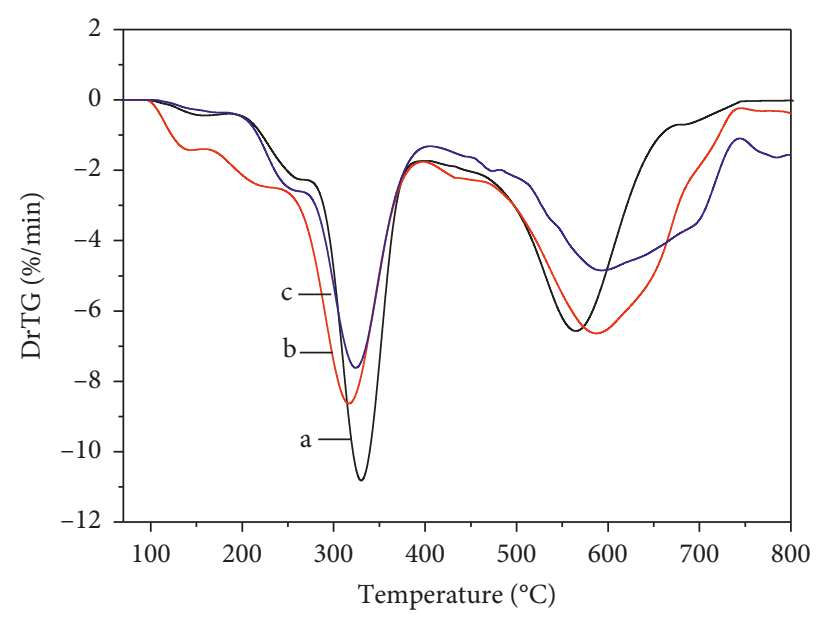

(a) Pure RPUF

(b) EG15-RPUF

(c) EG15-20A5-RPUF

(a)

(b)

Figure 4: (a) TGA and (b) DTG curves of pure PU foam and the PU composites.

EG15-RPUF composite, $T_{1 \max }$ decreased to $318^{\circ} \mathrm{C}$ that was assigned for the volatilization of the intercalated substances of EG, which started at about $300^{\circ} \mathrm{C}$. For EG15-20A5-RPUF composite, the first maximum weight loss took place at $315^{\circ} \mathrm{C}$, due to the decomposition of the ammonium modifier in the clay. The second maximum weight loss temperature $T_{2 \max }$ of pure PU, EG15-RPUF, and EG15-20A5-RPUF was about 568,574 , and $585^{\circ} \mathrm{C}$, respectively. The thermal stability of EG15-RPUF sample was slightly improved compared to the pure counterpart resulting from char formation of EG at a high temperature which slowed down the decomposition of the polymer. In the case of EG15-20A5-RPUF composite, organoclay constituted nanostructured barriers that delayed the diffusion of volatiles. As a result, the EG/clay/RPUF composite had better thermal stability than the EG/RPUF composite.

3.3. Mechanical Properties. To evaluate the mechanical properties of the pure RPUF and the RPUF composites, the compressive strength of the foams was measured, and the result is shown in Figure 5 and Table 2. These data showed that the presence of $15 \mathrm{wt} \%$ EG significantly reduced the compressive strength of RPUF from $0.2464 \mathrm{MPa}$ to $0.2313 \mathrm{MPa}$ at $10 \%$ strain. This may have been owing to the fact that microsized EG flakes caused the low compatibility between EG and the polyurethane polymer matrix. Furthermore, the big size of EG particles induced an inhomogeneous cell structure of the foam which affects the mechanical stability of the cellular structure. The result was consistent with previous reports [22-24].

By contrast, the compressive strength of the EG-PU foam increased upon adding clay. In particular, by adding $2.5 \mathrm{wt} \%$ clay to EG15-RPUF, the compressive strength of the EG15-20A2.5 composite increased notably from $0.2313 \mathrm{MPa}$

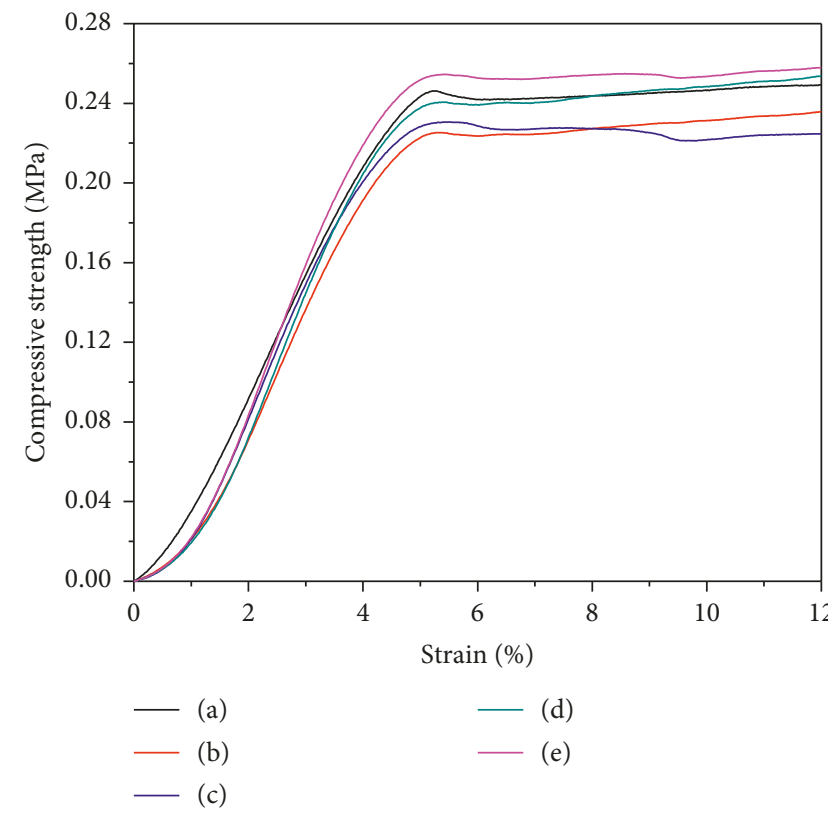

FIgURE 5: The compressive strength of the PU foams: (a) pure RPUF; (b) EG15-RPUF; (c) EG20-RPUF; (d) EG15-20A2.5RPUF; (e) EG15-20A5-RPUF.

to $0.2485 \mathrm{MPa}$, which is comparable to neat $\mathrm{PU}$ foam. A further addition to $5 \mathrm{wt} \%$ clay, the compressive strength of EG15-20A5RPUF displayed a slight increase to $0.2536 \mathrm{MPa}$. As shown in Figure 6(a), the $2 \theta$ peak of pure clay is $2.8^{\circ}$. According to Bragg's Law, the calculated $d$-spacing (d001) of clay is $31.5 \AA$, which is consistent with the datasheet of Cloisite 20A provided by the supplier Southern Clay Products Inc. However, there were no distinct features in the small angle XRD pattern of the clay/EG/PU composite. The result revealed silicate layers in nanometer size were mostly 


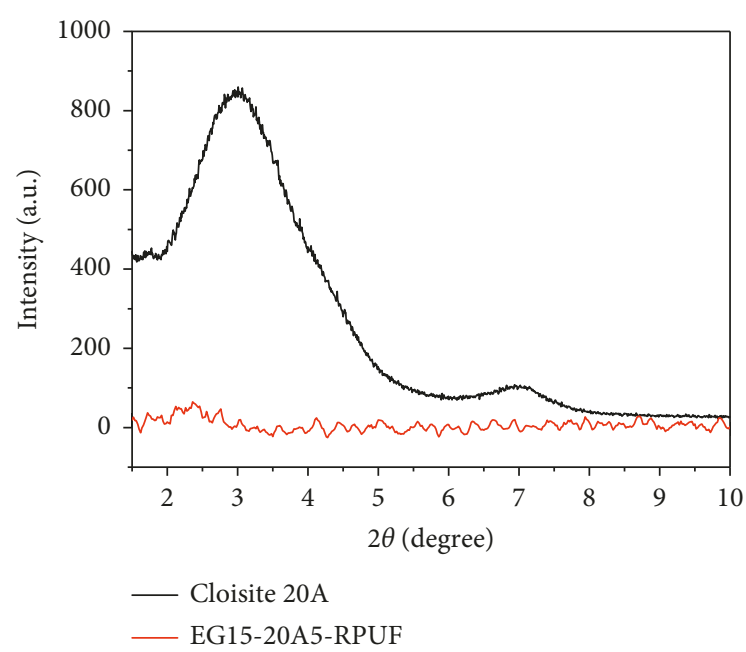

(a)

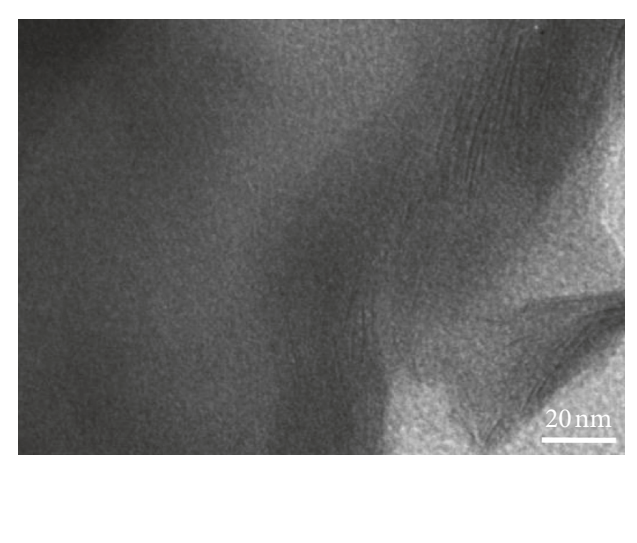

(b)

FIGURE 6: XRD patterns of clay and the RPUF composite (a) and TEM micrograph of EG15-20A5-RPUF composite (b).

exfoliated with a certain amount of intercalation in the PU matrix, which was further confirmed by TEM image (Figure 6(b)). The dispersion of exfoliated organoclay increased the interfacial interaction between clay and PU matrix that may enhance the compressive strength of the composite. In addition, the clay made polyol more viscous, which decreased the accumulation of EG, hence improving the dispersion of EG in the polymer. Thus, the presence of clay could enhance the compressive strength of the EG/PU composites.

3.4. Thermal Conductivity. The thermal conductivity of RPUF composites is represented in Figure 7 and Table 2. It was clear that adding EG filler to PU foam caused a significant increase in the thermal conductivity of PU composites. Adding $15 \mathrm{wt} \%$ EG increased the thermal conductivity of the EG15-RPUF composite by 90\%. If the content of EG was $20 \%$, the thermal conductivity increased to $0.058 \mathrm{~W} \cdot \mathrm{m}^{-1} \cdot \mathrm{K}^{-1}$, which was twice as much as pure RPUF. $\mathrm{EG}$ is a high thermal-conductive material, increasing the rate of heat transfer. As a result, EG impeded the insulation property of a PU foam.

The addition of clay reduced the thermal conductivity of the EG/RPUF composites. EG15-20A2.5-RPUF has a thermal conductivity of $0.048 \mathrm{~W} \cdot \mathrm{m}^{-1} \cdot \mathrm{K}^{-1}$, lower than that of EG15-RPUF $\left(0.053 \mathrm{~W} \cdot \mathrm{m}^{-1} \cdot \mathrm{K}^{-1}\right)$. The thermal conductivity of EG15-20A5-RPUF was further decreased by $23 \%$ compared to EG15-RPUF. It may have been due to the fact that silicate nanolayers created defects and formed effective barriers against the phonon transfer in the EG/PU matrix, therefore disrupting the thermal conducting network. The addition of organoclay seems to be a suitable method to improve the thermal insulation of the EG/RPUF composite.

\section{Conclusions}

In this work, flame retardancy, mechanical property, and thermal conductivity of the EG/RPUF and EG/organoclay/

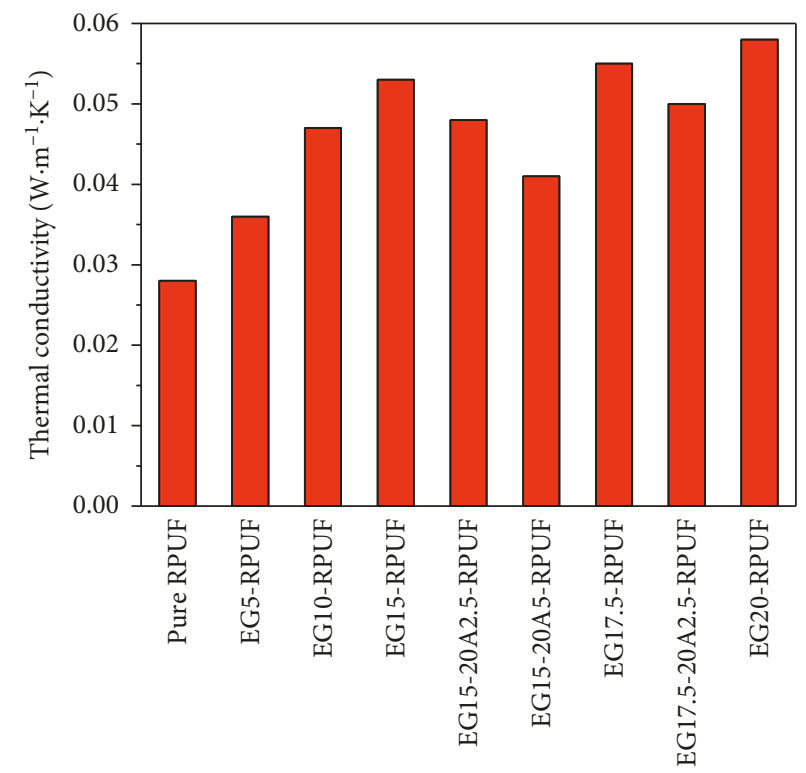

FIgURE 7: Thermal conductivity of pure RPUF and RPUF composites.

RPUF composites were investigated. Although the introduction of EG into the PU polymer matrix significantly enhanced the flame retardancy of the foam, the thermal insulation and compressive strength were reduced. Organoclay was incorporated into EG/PU composites to minimize this drawback. The LOI test indicated that, with the same EG content, the addition of organoclay could increase the LOI value of EG/PU foam. Furthermore, the compressive strength and thermal insulation of the composite were also improved in the presence of organoclay. The organoclay content of 2-3 wt\% was suitable to incorporate into EG/PU composite. The combination of EG and organoclay is a potential method for the fabrication of flame-retardant PU foams. This report could make a contribution to developing eco-friendly flameretardant PU products in the future. 


\section{Data Availability}

The data used to support the findings of this study are available from the corresponding author upon request.

\section{Conflicts of Interest}

The authors declare that there are no conflicts of interest regarding the publication of this paper.

\section{Acknowledgments}

This research was funded by the Vietnam Academy of Science and Technology under grant number "TĐPCCC.02/ 18-20."

\section{References}

[1] M. Thirumal, D. Khastgir, N. K. Singha, B. S. Manjunath, and Y. P. Naik, "Effect of foam density on the properties of water blown rigid polyurethane foam," Journal of Applied Polymer Science, vol. 108, no. 3, pp. 1810-1817, 2008.

[2] A. R. Kakroodi, M. Khazabi, K. Maynard, M. Sain, and O.-S. Kwon, "Soy-based polyurethane spray foam insulations for light weight wall panels and their performances under monotonic and static cyclic shear forces," Industrial Crops and Products, vol. 74, pp. 1-8, 2015.

[3] W. J. Seo, H. C. Jung, J. C. Hyun et al., "Mechanical, morphological, and thermal properties of rigid polyurethane foams blown by distilled water," Journal of Applied Polymer Science, vol. 90, no. 1, pp. 12-21, 2003.

[4] W. J. Seo, J. H. Park, Y. T. Sung, D. H. Hwang, W. N. Kim, and H. S. Lee, "Properties of water-blown rigid polyurethane foams with reactivity of raw materials," Journal of Applied Polymer Science, vol. 93, no. 5, pp. 2334-2342, 2004.

[5] K. Pielichowski, K. Kulesza, and E. M. Pearce, "Flammability of rigid polyurethane foams blown with penatane: limiting oxygen index data and thermovision charateristic," Journal of Polymer Engineering, vol. 22, no. 3, pp. 195-207, 2002.

[6] S. Duquesne, M. L. Bras, S. Bourbigot et al., "Expandable graphite: a fire retardant additive for polyurethane coatings," Fire and Materials, vol. 27, no. 3, pp. 103-117, 2003.

[7] C. Y. H. Chao and J. H. Wang, "Comparison of the thermal decomposition behavior of a non-fire retarded and a fire retarded flexible polyurethane foam with phosphorus and brominated additives," Journal of Fire Sciences, vol. 19, no. 2, pp. 137-156, 2001.

[8] M. Ravey and E. M. Pearce, "Flexible polyurethane foam. III. Phosphoric acid as a flame retardant," Journal of Applied Polymer Science, vol. 74, no. 5, pp. 1317-1319, 1999.

[9] M. Ravey, I. Keidar, E. D. Weil, and E. M. Pearce, "Flexible polyurethane foam. II. Fire retardation by tris(1,3-dichloro-2propyl) phosphate part A. Examination of the vapor phase (the flame)," Journal of Applied Polymer Science, vol. 68, no. 2, pp. 217-229, 1998.

[10] S. Hörold, "Phosphorus-based and intumescent flame retardants," Polymer Green Flame Retardants, vol. 22, pp. 221254, 2014.

[11] X. Shi, S. Jiang, J. Zhu, G. Li, and X. Peng, "Establishment of a highly efficient flame-retardant system for rigid polyurethane foams based on bi-phase flame-retardant actions," RSC Advances, vol. 8, no. 18, pp. 9985-9995, 2018.
[12] D. Price, Y. Liu, G. J. Milnes, R. Hull, B. K. Kandola, and A. R. Horrocks, "An investigation into the mechanism of flame retardancy and smoke suppression by melamine in flexible polyurethane foam," Fire and Materials, vol. 26, no. 45, pp. 201-206, 2002.

[13] M. Modesti, A. Lorenzetti, F. Simioni, and G. Camino, "Expandable graphite as an intumescent flame retardant in polyisocyanurate-polyurethane foams," Polymer Degradation and Stability, vol. 77, no. 2, pp. 195-202, 2002.

[14] V. Babrauskas, R. Fuoco, and A. Blum, "Flame retardant additives in polymers," Polymer Green Flame Retardants, vol. 22, pp. 87-118, 2014.

[15] M. Thirumal, D. Khastgir, N. K. Singha, B. S. Manjunath, and Y. P. Naik, "Effect of expandable graphite on the properties of intumescent flame-retardant polyurethane foam," Journal of Applied Polymer Science, vol. 110, no. 5, pp. 2586-2594, 2008.

[16] L. Shi, Z.-M. Li, B.-H. Xie, J.-H. Wang, C.-R. Tian, and M.-B. Yang, "Flame retardancy of different-sized expandable graphite particles for high-density rigid polyurethane foams," Polymer International, vol. 55, no. 8, pp. 862-871, 2006.

[17] L. Shi, Z.-M. Li, W. Yang, M.-B. Yang, Q.-M. Zhou, and R. Huang, "Properties and microstructure of expandable graphite particles pulverized with an ultra-high-speed mixer," Powder Technology, vol. 170, no. 3, pp. 178-184, 2006.

[18] X.-C. Bian, J.-H. Tang, Z.-M. Li, Z.-Y. Lu, and A. Lu, "Dependence of flame-retardant properties on density of expandable graphite filled rigid polyurethane foam," Journal of Applied Polymer Science, vol. 104, no. 5, pp. 3347-3355, 2007.

[19] H. Yang, H. Liu, Y. Jiang, M. Chen, and C. Wan, "Density effect on flame retardancy, thermal degradation, and combustibility of rigid polyurethane foam modified by expandable graphite or ammonium polyphosphate," Polymers, vol. 11, no. 4 , p. $668,2019$.

[20] P. Acuña, Z. Li, M. Santiago-Calvo, F. Villafañe, M. Ángel Rodríguez-Perez, and De-Y. Wang, "Influence of the characteristics of expandable graphite on the morphology, thermal properties, fire behaviour and compression performance of a rigid polyurethane foam," Polymers, vol. 11, p. 168, 2019.

[21] M. Modesti and A. Lorenzetti, "Improvement on fire behaviour of water blown PIR-PUR foams: use of an halogenfree flame retardant," European Polymer Journal, vol. 39, no. 2, pp. 263-268, 2003.

[22] L. Shi, Z.-M. Li, M.-B. Yang et al., "Expandable graphite for halogen-free flame-retardant of high-density rigid polyurethane foams," Polymer-Plastics Technology and Engineering, vol. 44, no. 7, pp. 1323-1337, 2005.

[23] X.-C. Bian, J.-H. Tang, and Z.-M. Li, "Flame retardancy of hollow glass microsphere/rigid polyurethane foams in the presence of expandable graphite," Journal of Applied Polymer Science, vol. 109, no. 3, pp. 1935-1943, 2008.

[24] X.-Y. Meng, L. Ye, X.-G. Zhang et al., "Effects of expandable graphite and ammonium polyphosphate on the flameretardant and mechanical properties of rigid polyurethane foams," Journal of Applied Polymer Science, vol. 114, no. 2, pp. 853-863, 2009.

[25] P. S. Khobragablr, D. P. Hansora, J. B. Naik, and A. Chatterjee, "Flame retarding performance of elastomeric nanocomposites: a review," Polymer Degradation and Stability, vol. 130, pp. 194-244, 2016.

[26] A. Kausar, "Polyurethane composite foams in highperformance applications: a review," Polymer-Plastics Technology and Engineering, vol. 57, no. 4, pp. 346-369, 2018.

[27] M. Modesti, A. Lorenzetti, S. Besco et al., "Synergism between flame retardant and modified layered silicate on thermal 
stability and fire behaviour of polyurethane nanocomposite foams," Polymer Degradation and Stability, vol. 93, no. 12, pp. 2166-2171, 2008.

[28] H. Kadam, S. Bandyopadhyay-Ghosh, N. Malik, and S. B. Ghosh, "Bio-based engineered nanocomposite foam with enhanced mechanical and thermal barrier properties," Journal of Applied Polymer Science, vol. 136, no. 7, pp. 47063-47069, 2018.

[29] Z. Sun, Y. Ma, Y. Xu et al., "Effect of the particle size of expandable graphite on the thermal stability, flammability, and mechanical properties of high-density polyethylene/ ethylene vinyl-acetate/expandable graphite composites," Polymer Engineering \& Science, vol. 54, no. 5, pp. 1162-1169, 2014.

[30] Y. F. Zhao, M. Xiao, S. J. Wang, X. C. Ge, and Y. Z. Meng, "Preparation and properties of electrically conductive PPS/ expanded graphite nanocomposites," Composites Science and Technology, vol. 67, no. 11-12, pp. 2528-2534, 2007.

[31] T. Widya and C. W. Macosko, "Nanoclay-modified rigid polyurethane foam," Journal of Macromolecular Science, Part $B$, vol. 44, no. 6, pp. 897-908, 2005.

[32] S. Ganguli, A. K. Roy, and D. P. Anderson, "Improved thermal conductivity for chemically functionalized exfoliated graphite/epoxy composites," Carbon, vol. 46, no. 5, pp. 806817,2008 

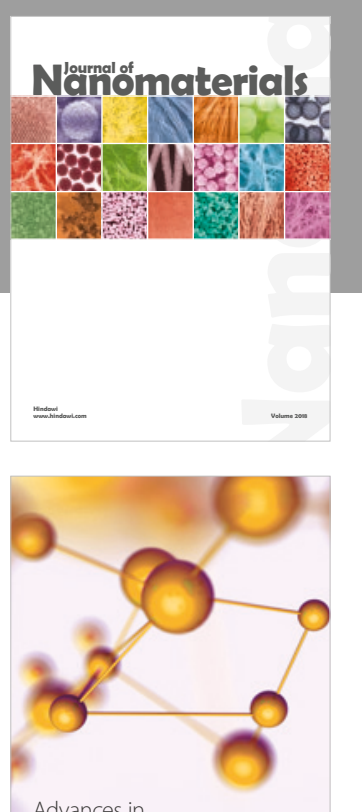

Physical Chemistry
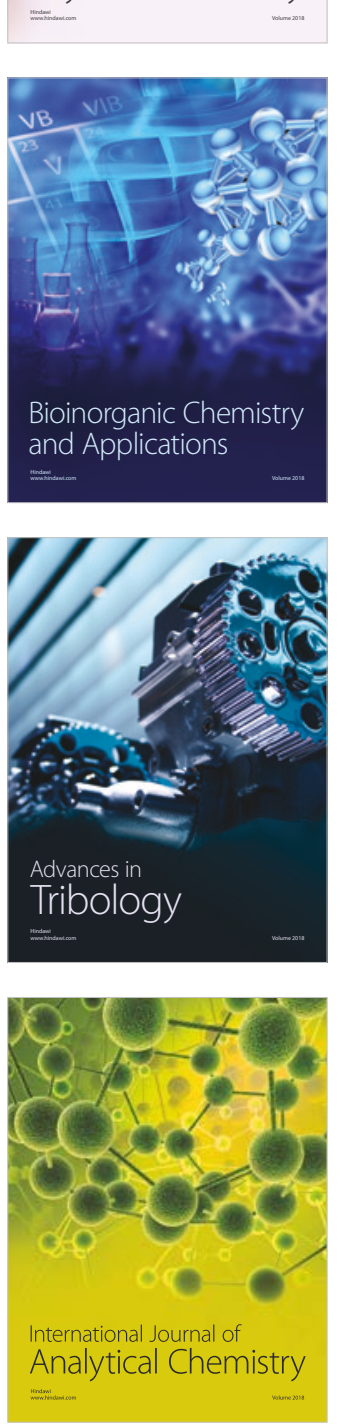

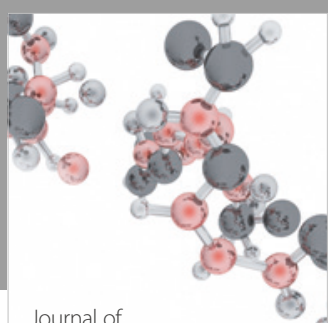

Analytical Methods

in Chemistry

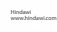

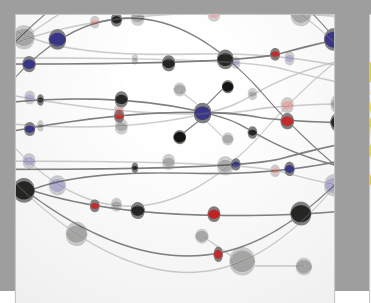

The Scientific World Journal

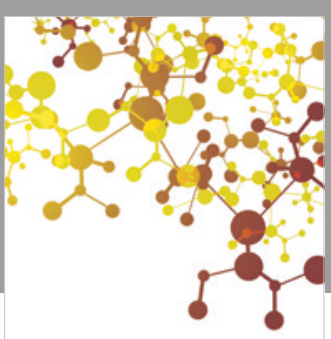

Journal of

Applied Chemistry
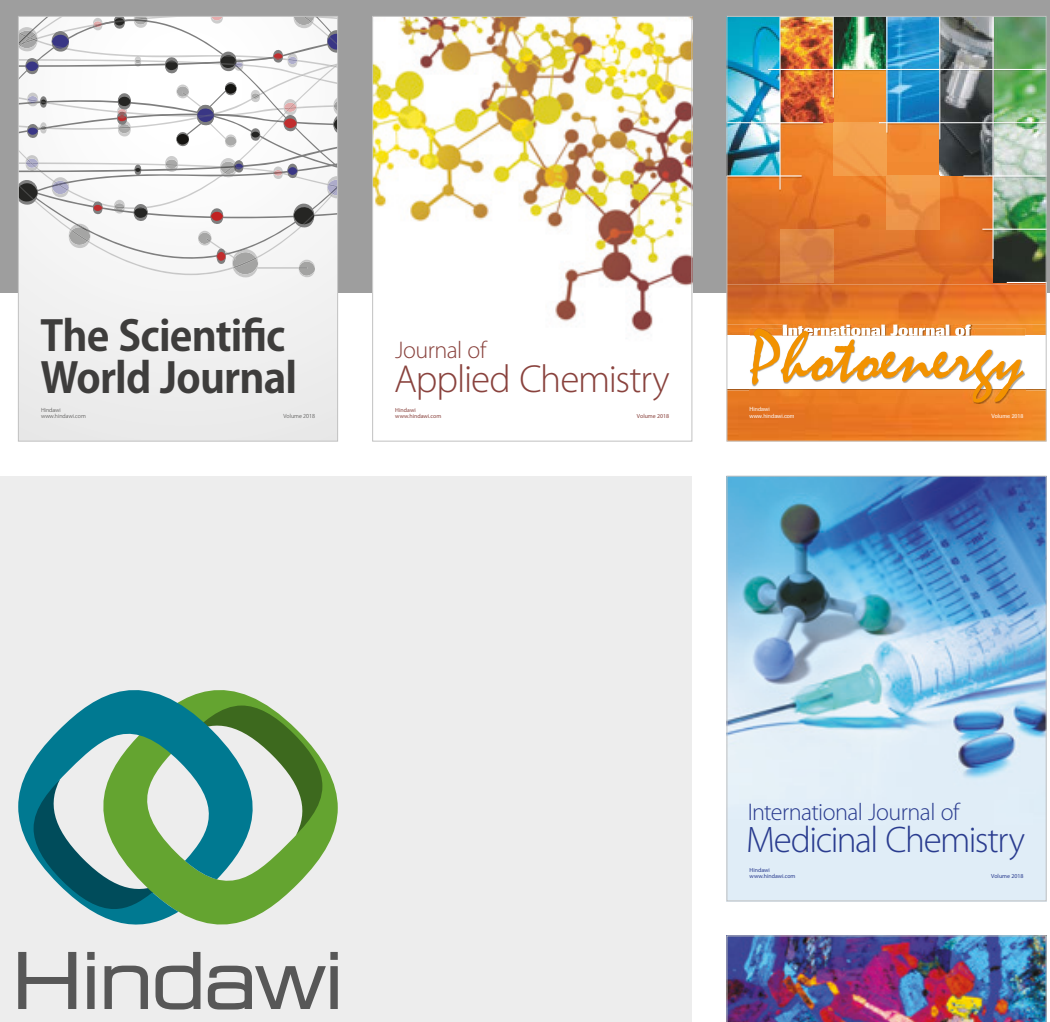

Submit your manuscripts at

www.hindawi.com
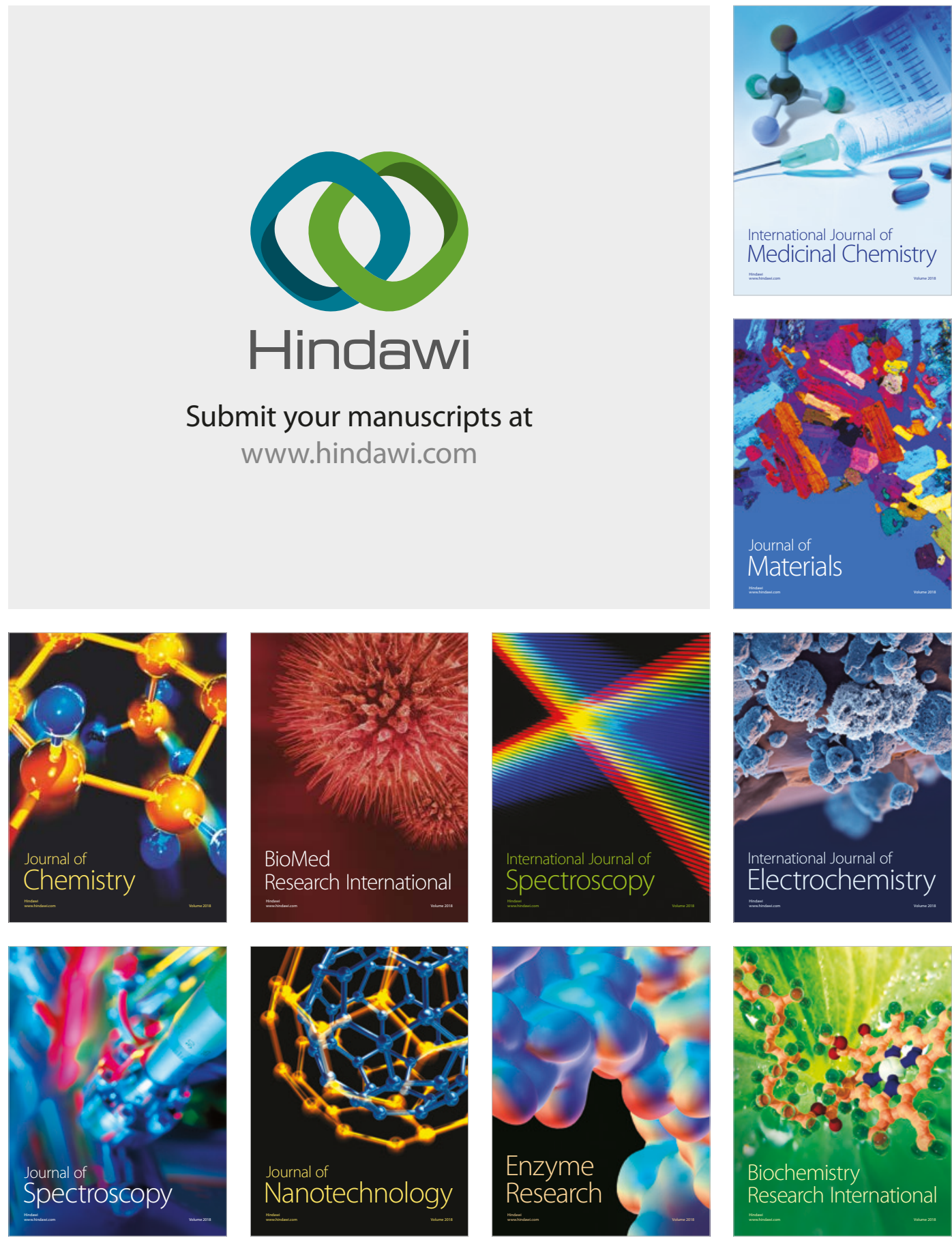
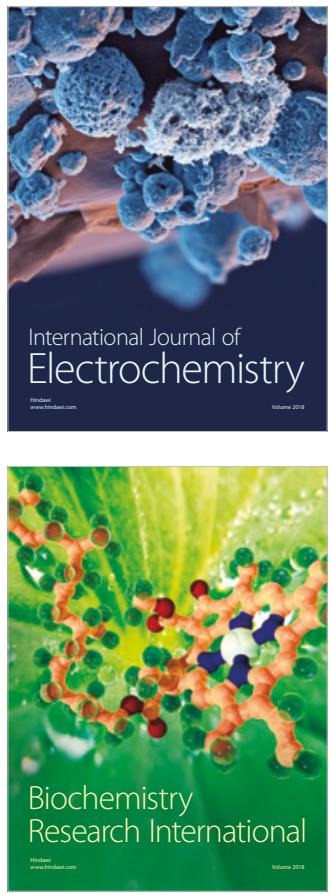